\title{
O empoderamento docente e a aproximação entre a Universidade e a Escola: alguns desafios
}

\author{
Teacher empowerment and the approximation between College and \\ School: some challenges
}

\section{El empoderamento de los docentes y la aproximación entre la universidad y la escuela: algunos desafíos}

\author{
Patrícia Sandalo Pereira' \\ Universidade Federal do Mato Grosso do Sul, Instituto de Matemática, Professora e Diretora. \\ https://orcid.org/0000-0002-7554-0058 \\ Kely Fabrícia Pereira Nogueira ${ }^{2}$ \\ Prefeitura Municipal de Campo Grande, Professora. \\ https://orcid.org/0000-0002-1006-0109 \\ Nickson Moretti Jorge ${ }^{3}$ \\ Rede Estadual de Ensino de São Paulo, Professor. \\ https://orcid.org/0000-0001-9013-7163
}

Resumo: Neste artigo, considerando o atual contexto sócio-politico brasileiro, trazemos à tona temas como o empoderamento docente e a aproximação entre a Universidade e a Escola, enquanto desafios enfrentados no decorrer da formação inicial de professores de Matemática. Desse modo, ponderamos que o empoderamento docente evidencia possibilidades de uma possível autonomia em relação ao profissional professor (técnico, reflexivo e intelectual crítico). Quanto a aproximação entre a Universidade e a Escola, traremos as perspectivas de parceria na formação de professores, são elas: dirigida, oficial e colaborativa. Com essa compreensão, procuramos aproximar os contextos de formação à realidade do professor, buscando possibilidades reais de investigação, a partir da visão de unidade entre teoria e prática, pesquisa e formação, universidade e educação básica. Nessa perspectiva, o referencial teórico e metodológico traz, em seu bojo, a colaboração, a reflexão crítica e a produção de conhecimento vinculadas a sua natureza dialógica, o que nos possibilita a construção de um percurso em que tais ações sejam capazes de contribuir para a profissionalização do professor, de modo a viabilizar o aprimoramento de saberes necessários para a busca de caminhos e respostas aos inúmeros desafios e necessidades de sua ação pedagógica, perspectivando um sujeito em estado de consciência crítica e engajado na transformação de

Doutora e Mestre em Educação Matemática pela Universidade Estadual Paulista Júlio de Mesquita Filho.

Doutora e Mestre em Educação Matemática pela Universidade Federal de Mato Grosso do Sul.

Doutor e Mestre em Educação Matemática pela Universidade Federal de Mato Grosso do Sul. 
sua realidade. A partir dessas discussões, as análises levaram-nos a concluir que é necessário que a universidade propicie a esses profissionais a compreensão de seu verdadeiro papel social, na tentativa de compreender-nos criticamente em relação aos valores e as práticas que atuamos.

Palavras-chave: Educação Matemática. Formação de Professores. Autonomia. Parceria. Pesquisa Colaborativa.

Abstract: In this article, considering the current brazilian socio-political context, we bring up topics such as teacher empowerment and the approximation between College and School, as challenges faced during the initial formation of mathematics teachers. Thus, we consider that teacher empowerment promoves possibilities for a possible autonomy in the relation to the professional teacher Itechnical, reflective and critical intellectuall. About the approximation between College and School, we will introduce the perspectives of partnership in the training of teachers, they are: directed, official and collaborative. From that understanding, we seek to introduce the contexts of formation closer to the reality of the teacher, seeking real possibilities of investigation, from the view of unity between theory and practice, research and training, College and Midle / High School. In this perspective, the theoretical and methodological framework brings, in its core, collaboration, critical reflection and the production of knowledge linked to its dialogical nature, which allows us to build a path in which these actions were able to contribute to the professionalization of the teacher, in order to enable the improvement of the necessary knowledge to search for ways and answers to the countless challenges and needs of his pedagogical action, putting in perspective a subject in a state of critical awareness and engaged in the transformation of his reality. Based on these discussions, the analyzes led us to conclude that it is necessary for the College to provide these professionals with an understanding of their true social role, in an attempt to understand critically their relation between the values and practices they operate. Keywords: Mathematical Education. Teacher Formation. Autonomy. Partnership. Collaborative Research.

Resumen: En este artículo, considerando el contexto sociopolitico brasileño actual, presentamos temas como el empoderamiento de los docentes y la aproximación entre la Universidad y la Escuela, como desafios enfrentados durante la formación inicial de los docentes de matemáticas. Por lo tanto, consideramos que el empoderamiento del docente muestra posibilidades de una posible autonomía en relación con el docente profesional lintelectual técnico, reflexivo y críticol. En cuanto a la aproximación entre la Universidad y la Escuela, aportaremos las perspectivas de colaboración en la formación de docentes, que son: dirigidas, oficiales y colaborativas. Con esta comprensión, buscamos acercar los contextos de formación a la realidad del profesor, buscando posibilidades reales de investigación, desde la perspectiva de la unidad entre teoría y práctica, investigación y formación, universidad y educación básica. En esta perspectiva, el marco teórico y metodológico aporta, en su núcleo, la colaboración, la reflexión crítica y la producción de conocimiento vinculado a su naturaleza dialógica, lo que nos permite construir un camino en el que dichas acciones pueden contribuir a la La profesionalización del profesor, a fin de permitir la mejora del conocimiento necesario para buscar formas y respuestas a los innumerables desafios y necesidades de su acción pedagógica, imaginando un tema en un estado de 
conciencia crítica y comprometido en la transformación de su realidad. Con base en estas discusiones, los análisis nos llevaron a concluir que es necesario que la universidad brinde a estos profesionales una comprensión de su verdadero papel social, en un intento de comprendernos críticamente en relación con los valores y prácticas que operamos.

Palabras clave: Educación matemática. Formación de profesores. Autonomía. Sociedad. Investigación colaborativa.

Recebido em 17 de março de 2020

Aceito em 15 de outubro de 2020

\section{INTRODUÇÃO}

0 que escrevemos naturalmente está impresso em nós. É originado do lugar que viemos e estamos, não do lugar geográfico, mas naturalmente do lugar que estamos situados, como seres vivos históricos e dialógicos. Deste espaço, compreendemos o mundo pelo viés da matéria. Escrevemos como professores, pesquisadores, orientadores de pesquisas sobre a formação de professores de Matemática, com uma consciência crítica da real situação do sujeito professor em relação ao seu não álibi e, conforme pondera Contreras (2012), com a consciência não só do compromisso com a transmissão de um saber crítico, mas com a própria transformação social, por meio da capacitação para pensar e agir criticamente.

Para o presente artigo, trazemos à tona temas como o empoderamento docente e a aproximação entre a Universidade e a Escola, enquanto desafios enfrentados no decorrer da formação inicial de professores de Matemática. Desse modo, consideramos que o empoderamento docente evidencia viabilidades para uma possível autonomia, baseados, neste sentido, nos estudos de Contreras (2012) em relação ao profissional professor (técnico, reflexivo e intelectual crítico). Quanto a aproximação entre a Universidade e a Escola, traremos as perspectivas de parceria na formação de professores, são elas: dirigida, oficial e colaborativa.

Com essa compreensão, buscamos alternativas para aproximar os contextos de formação à realidade do professor, procurando possibilidades reais de investigação, a partir da visão de unidade entre: teoria e prática, pesquisa e formação, e universidade e educação básica.

0 referencial teórico-metodológico deriva de três campos intrinsecamente ligados: formação inicial de professores, empoderamento docente e as parcerias entre a Universidade e a escola, trazendo, em seu bojo, a colaboração, a reflexão crítica e a produção de conhecimento; vinculada a sua natureza dialógica, o que nos possibilita a construção de um percurso em que tais ações sejam capazes de contribuir para a profissionalização do 
professor, de modo a possibilitar o aprimoramento de saberes necessários para a busca de caminhos e respostas aos inúmeros desafios e necessidades de sua ação pedagógica, perspectivando um sujeito em estado de consciência crítica e engajado na transformação de sua realidade.

\section{O EMPODERAMENTO DOCENTE}

A formação inicial de professores de Matemática tem sido um dos temas mais discutidos na atualidade. Nas últimas décadas, vários estudos foram realizados, problematizando diversos aspectos dessa formação.

Gatti (1997, p. 90) afirma que é necessário "[...] reconhecer que não se pode fazer educação e ensino sem profissionais devidamente preparados para este trabalho, em qualquer modalidade que se opte por desenvolver este ensino."

Consideramos que a formação inicial deve ser formativa, de modo a desenvolver o profissionalismo docente para que tenhamos uma educação e um ensino de qualidade e, para isso, temos de compreender as necessidades da comunidade em que o professor trabalha/ vivencia, pois, assim, poderemos desenvolver práticas que mobilizem o processo de ensino aprendizagem dos alunos.

Na formação inicial, devemos levar os acadêmicos a compreender as necessidades do atual sistema educacional, considerando os conhecimentos prévios e o contexto sóciopolítico em meio às diferentes realidades socioculturais e econômicas nas quais irão trabalhar. Sendo assim, a formação inicial deve possibilitar análises reflexivas do sistema educacional, dos múltiplos afazeres docentes, enfim da realidade com uma bagagem de conhecimentos específicos para que, no processo formativo, os professores assumam as tarefas diárias da profissão docente. Considera-se que uma formação que não forme profissionais para contribuírem reflexivamente para as mudanças do sistema, poderá formar professores que se sentirão deslocados e inaptos para desenvolver as suas funções, vindo a abandonar o ensino (PONTE, 2002).

Para Imbernón (2011), a autonomia é definida como poder de decisão do professor referente as suas práticas e possíveis mudanças delas, para além de uma participação formal e burocrática nas formações e ações do cotidiano escolar, mas em desenvolver ações transformadoras tanto no processo de ensino - aprendizagem dos alunos como nas próprias formações. 
Compreendemos a autonomia como a capacidade do professor em desenvolver a sua atividade profissional, acordado com o sistema de trabalho no qual está vinculado.

De acordo com Imbernón e Cauduro (2013, p. 25), "[...] o conceito de autonomia na colegialidade, e a autonomia de cada um dos professores e professoras só é compatível se for vinculada a um projeto comum e a processos autônomos de formação e desenvolvimento profissional."

Neste sentido, discutimos a formação inicial desse profissional e suas ações pedagógicas no contexto atual da educação nacional, sobretudo como se dá a coligação ensino e aprendizagem diante das novas exigências para a área, buscando refletir sobre o empoderamento docente, evidenciando a viabilidade para uma possível autonomia, embasados na visão de Contreras em relação ao profissional professor (técnico, reflexivo e intelectual crítico).

Compreendemos que o professor é visto como um profissional capaz de transformar sua prática por meio da reflexão crítica, ato consciente e construir novos saberes a partir das suas experiências, das suas histórias de vida, do meio no qual está inserido. No entanto, entendemos que as possibilidades estão imbricadas na vida desse profissional.

É notório que o professor, em sua formação inicial, não é, de fato, bem preparado, principalmente no que tange à Educação Matemática, visto as possibilidades reais que se tem apresentado nesse tempo/espaço. Porém, as tentativas também são inúmeras de superar as necessidades explicitadas por esses profissionais, possibilitando mais autonomia e empoderamento no viés de conhecimentos e saberes.

Nóvoa (1995) esclarece que há necessidade de professores que não trilhem o caminho da imitação, mas que se comprometam e reflitam sobre a educação e a sociedade, professores que fazem a diferença em sua profissão, que não sejam meramente técnicos, mas criadores. Pondera também que a formação de professores “[...] precisa ser repensada e reestruturada como um todo, abrangendo as dimensões iniciais, da indução e da formação contínua [...]" (NÓVOA, 1995, p. 26). 0 autor sugere a integração dos seguintes níveis no processo formativo dos professores (Figura 1). 
Figura 1 - Niveis de conceitos

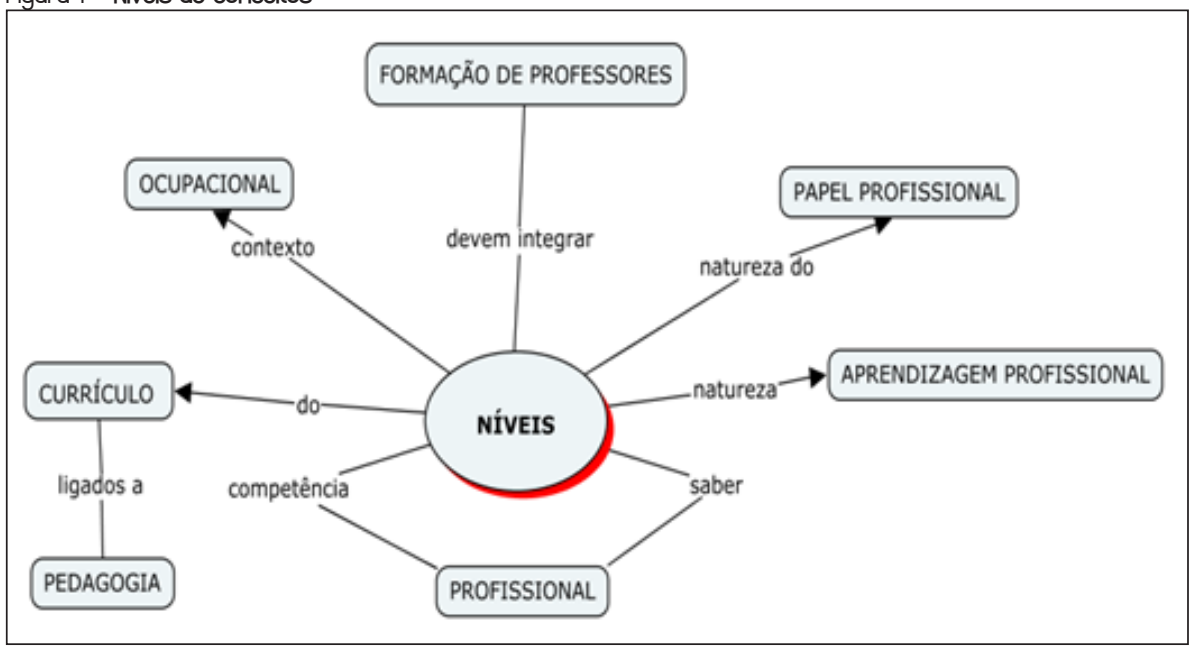

Fonte: elaborada pelos autores com base em Nóvoa (1995).

Compreendemos que a formação de professores deve integrar a conceituação desses níveis, mas entendemos que tanto as Universidades como as escolas de educação básica são incapazes de concretizar essa formação de forma isolada, é necessário - estabelecimento de parcerias para responder a essas necessidades. Parcerias na perspectiva colaborativa, como aponta Nogueira (2019, p. 103),

\footnotetext{
[...] cria condições para que os sujeitos, partícipes e as instituições estabeleçam negociações concretas, construam $\circ$ conhecimento, partilhando, reflexivamente, respeitando os interesses específicos, discutindo e interferindo no discurso dos outros, vislumbrando uma real conexão entre universidade/escola, ambos espaços formados por sujeitos vivos e comunicativos.
}

No entanto, compreender essa parceria em tal perspectiva é, antes de tudo, entendermos as concepções diferentes sobre a profissão professor, as quais Contreras (2012) estabelece como especialista técnico, profissional reflexivo e intelectual crítico; visto que cada uma dessas concepções possui a compreensão das dimensões profissionais, tais como: obrigação moral, compromisso com a comunidade e a competência profissional (CONTRERAS, 2012) com abordagens diferentes (Figuras 2, 3 e 4). 
Figura 2 - Obrigação Moral

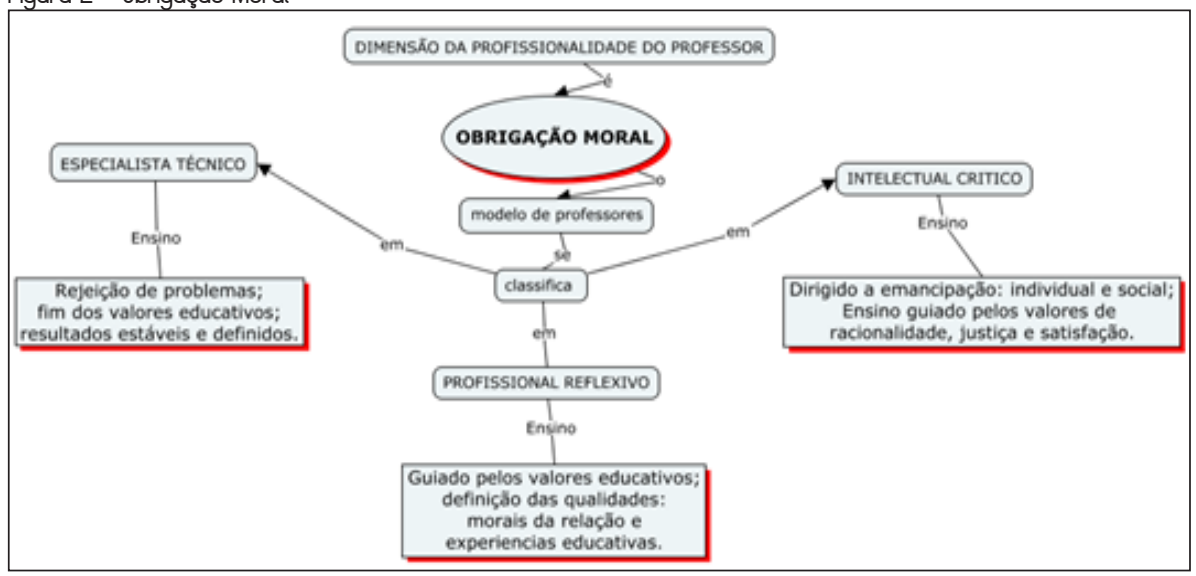

Fonte: elaborada pelos autores com base em Contreras (2012).

Segundo Contreras (2012), essa é a primeira dimensão da profissionalidade docente, que deriva do fato que o ensino supõe compromisso moral, para quem o realiza, visto que todas as ações que os professores realizam são cheias de intenções, e quase tudo que fazemos tem consequências morais, visto que o fato inevitável do trabalho docente está em relação direta com outros sujeitos, os quais influenciamos e somos influenciados. A esse respeito, Contreras (2012, p. 86-87) assevera:

0 professor ou professora tem inevitavelmente se defrontar com suas próprias decisões sobre a prática que realiza, porque ao ser ele ou ela quem pessoalmente se projeta em suas relações com os alunos e alunas, tratando de gerar uma influência, deve decidir ou assumir o grau de identificação ou de compromisso com as práticas educativas que desenvolve, seus níveis de transformação da realidade que enfrenta [...] 
Figura 3 - Compromisso com a comunidade

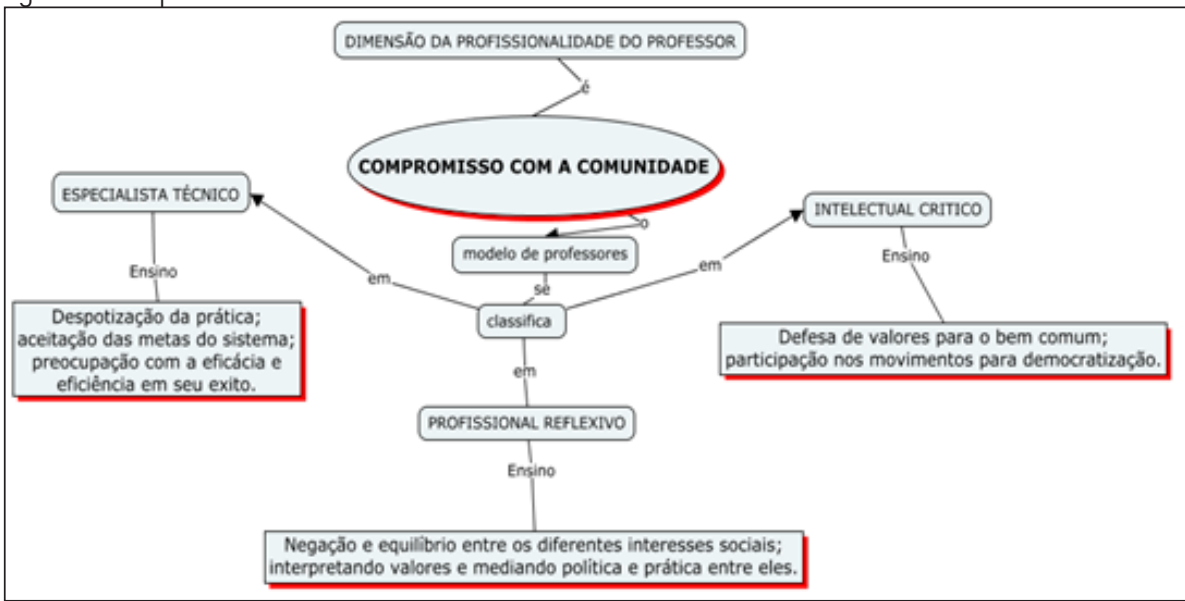

Fonte: elaborada pelos autores com base em Contreras (2012).

Segundo Contreras (2012), essa é a segunda dimensão da profissionalidade docente que deriva da relação com a comunidade social, na qual os professores realizam as suas ações profissionais. Sabemos que a moralidade não é um fato isolado, logo as ações profissionais não se constituem como soltas, isoladas, mas ações conjuntas e partilhadas.

Assim, a profissionalidade dos professores diante do legítimo direito da comunidade a intervir na educação consiste em interpretar as expectativas sociais como parte de suas ações no processo de mediar conflitos, de maneira a entender o sentido de cada posição no contexto escolar, visto que essas ações têm efeito sobre a vida dos sujeitos, o que é próprio das ações docentes. Neste sentido, Contreras (2012, p. 90 - 91) assegura que

[...] as instituições educativas são lugares nos quais alunos e alunas se introduzem em formas particulares de vida [...]; se a escola é uma instituição que desempenha funçães de regulação social e de seleção [...] a prática docente pode incluir dentro de sua própria reflexão e ação a forma em que estes valores politicos se realizam[...] formação nas atitudes e valores básicos cidadãos. [...] a escola é justificada como uma instituição encarregada de proporcionar oportunidade sociais por meios educativos. 
Figura 4 - Competência Profissional

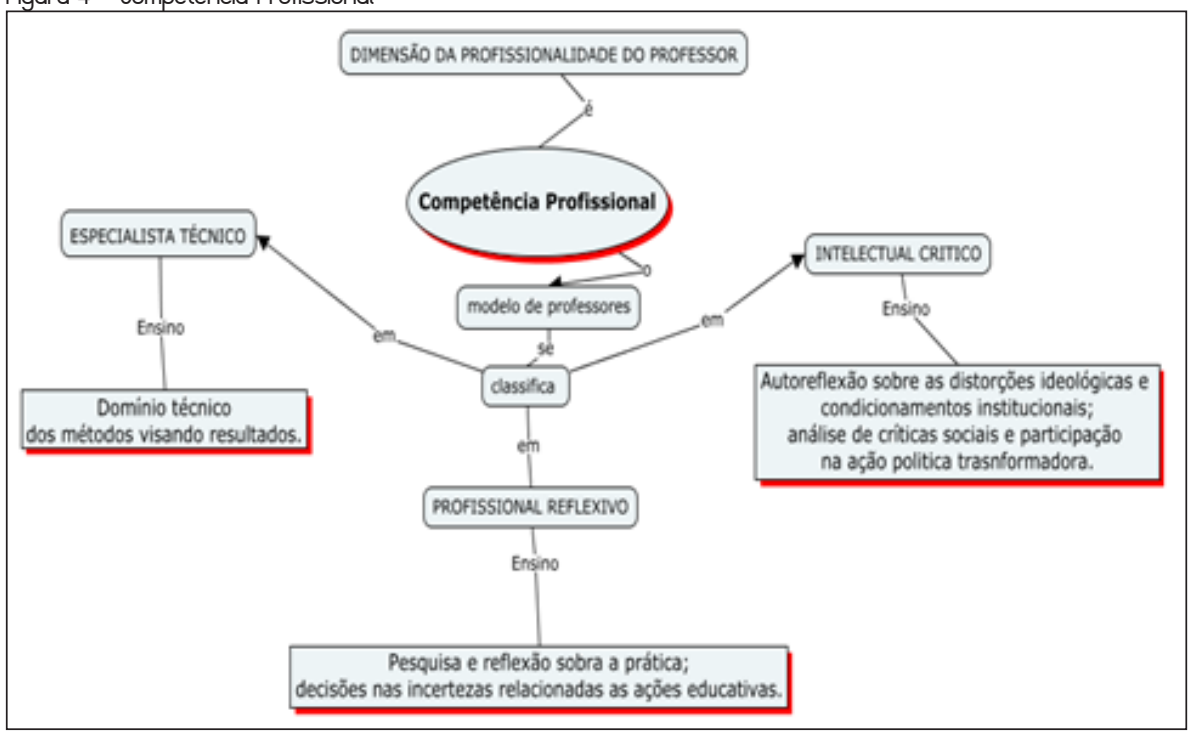

Fonte: elaborada pelos autores com base em Contreras (2012).

Segundo Contreras (2012), essa é a terceira dimensão da profissionalidade docente visto que só é possível se o professor tiver uma obrigação moral e o compromisso com a comunidade.

Logo é mister compreender que a competência profissional não se refere apenas ao "capital de conhecimento disponível, mas também aos recursos intelectuais de que se dispõe com o objetivo de tornar possível a ampliação e desenvolvimento desse conhecimento profissional, sua flexibilidade e profundidade." (CONTRERAS, 2012, p. 93).

São necessárias a análise e a reflexão sobre as ações profissionais, pois o meio influencia-nos, como também nós o influenciamos. Torna-se imperativo reconhecer a capacidade de ações reflexivas e as possibilidades de transformações de conhecimentos sobre suas ações e o seu papel. Sobre esse aspecto, Brousseau (2008, p. 43) explicita apontamentos acerca do papel do professor, enfatizando que:

0 professor realiza primeiro o trabalho inverso ao do cientista, uma recontextualização do saber: procura situações que deem sentido aos conhecimentos que devem ser ensinados. Porém, se a fase de personalização funcionou bem, quando o aluno respondeu às situações propostas não sabia que o que "produziu" é um conhecimento que poderá utilizar em outras ocasiões. Para transformar suas respostas e seus conhecimentos em saber deverá, com a ajuda do professor, redespersonalizar e re-descontextualizar o saber que produziu, para poder 
reconhecer que fez algo que tenha caráter universal, um conhecimento cultural reutilizável.

Coadunamos com o autor e acrescentamos que a competência profissional é uma dimensão necessária para o desenvolvimento do compromisso ético e social, porque proporciona os recursos que a tornam possivel. Contreras (2012, p. 95) ao referir-se aos três aspectos, ou as três dimensões, sublinha que: "[...] podem ser concebidas e combinadas de maneiras diferentes em funções das concepções profissionais das quais se parta, e que dependem, por sua vez, da forma em que se entenda o ensino, seu contexto educacional, seus propósitos e sua realização."

Portanto, na perspectiva de Contreras, saber ser professor exige mais do que conhecimentos externos, técnicos, antecipados pela formação. 0 comportamento, a atitude, as ações desenvolvidas na prática real são evidências do processo a ser seguido no ato de ensinar. Quando nos permitimos dialogar, informando, descrevendo e permitindo o confronto de conhecimentos, temos possibilidades de superar uma autonomia utópica, permitindo uma consciência crítica.

Assim, com essas dimensões esclarecidas, as concepções sobre a profissão professor: como especialista técnico, profissional reflexivo e intelectual crítico trazem os seguintes entendimentos sobre a autonomia profissional.

$\mathrm{Na}$ concepção de especialista técnico, a autonomia é entendida como atributo, tendo a autoridade do especialista como unilateral. Nessa concepção, a autonomia é ilusória, o professor é reconhecido como um profissional técnico, a sua ação profissional está imbricada nas soluções instrumentais dos problemas.

Quando o docente é visto como técnico, a perspectiva que possui é lecionar sem uma preocupação política do seu papel social na sua atividade docente, não tendo uma autonomia real, sendo a sua atividade um modelo teórico de aplicação.

Ao se referir a esse profissional, Nogueira (2019, p. 111) afirma que "[...] relaciona ao conhecimento técnico sem possibilidades de mudanças, está relacionada a exagerada preocupação do desenvolvimento de um conhecimento teórico fechado, buscando soluções para os problemas diários, baseados em sugestões."

Dessa forma, há uma "[...] dependência de diretrizes técnicas, insensibilidade para os dilemas, incapacidade de respostas criativas diante das incertezas." (CONTRERAS, 2012, p. 211).

$\mathrm{Na}$ concepção de profissional reflexivo, a autonomia profissional é entendida como responsabilidade moral individual, que considera os diferentes pontos de vista. Possui equilibrio, coerência entre a independência de juízo e a responsabilidade social. Dessa forma, o importante dessa perspectiva, de acordo com Contreras (2012, p. 216), é que 
[...] a autonomia não é exatamente uma condição que se possui como requisito prévio à ação. Entendida como qualidade na forma pela qual nos conduzimos, entendida como circunstancialmente, a autonomia profissional é uma construção que fala tanto da forma pela qual se atua profissionalmente como dos modos desejáveis de relações sociais.

Nesse viés, a autonomia não é definição de características individuais, mas a maneira como se constituem e a forma que se relacionam. Destarte, a capacidade de resolver situações problemáticas das ações educativas de forma criativa.

0 docente reflexivo é aquele que desenvolve reflexão sobre as suas práticas, o qual até desenvolve mudanças no seu fazer docente, sendo compreendido como autonomia, quando a sua própria prática muda as ações que desenvolve como docente.

$\mathrm{Na}$ concepção de intelectual crítico, a autonomia profissional é entendida como emancipação, ou seja, liberação profissional e social das tensões e opressões.

0 docente como intelectual crítico é aquele capaz de refletir quanto a realidade que possui, buscando transformações nos aspectos coletivos, pois compreende o papel social e político da sua atividade, possuindo, dessa forma, uma autonomia no campo da emancipação.

Nesse sentido, a reflexão crítica é libertadora porque nos emancipa das visões acríticas, dos pressupostos, hábitos, tradições e costumes não questionados e das formas de coerção e de dominação que tais práticas supõem e que muitas vezes nós mesmos sustentamos, em um autoengano. (CONTRERAS, 2012, p. 181).

Para desenvolver a reflexão crítica nessa emancipação, requer-se viver a prática reflexiva implicando dominar habilidades, como o reconhecimento dos problemas, avaliar-se, construir ações transformadoras que possibilitem formar a crítica sobre a prática, os valores implícitos nessa prática, assim como os contextos e as suas repercussões, em um processo constante referente a uma realidade pela necessidade de compreensões, considerando as experiências anteriores, os conhecimentos já constituídos ou em vias de constituição (LBERAЦ, 2012).

Vários autores expressam as suas concepções em relação a reflexão crítica. Souza (2012) afirma que as características da reflexão crítica são a transformação social e as questões éticas. Refletir criticamente, para Ghedin (2002), significa enfrentar as situações das instituições, com relação às práticas docentes no contexto que vivenciamos socialmente. Para Liberali (2012), a reflexão crítica tem, como base, o autoconhecimento e uma oportunidade de reconstrução das próprias ações e de si. 
A reflexão crítica em um contexto social, político, está preocupada e visa compreender as necessidades reais, buscando a transformação pela autonomia e emancipação dos docentes.

Corroboramos com as autoras Magalhães e Liberali (2004) e Liberali (2012), considerando que, para o desenvolvimento da reflexão crítica, as ações de descrever, informar, confrontar e reconstruir são essenciais. Descrever constitui caminho para refletir a ação desenvolvida, referente à própria prática, conscientizando-se das próprias ações. Informar, princípio em compreender as metodologias, as teorias e as práticas que são desenvolvidas com relação ao processo da ação docente para o ensino aprendizagem dos alunos. Confrontar refere-se à sistematização das ações desenvolvidas pelo descrever e informar, compreendendo as teorias - práticas mobilizadas nas ações desenvolvidas para um real compreender com relação social do que foi realizado. Reconstruir configura-se como confronto em que as compreensões mobilizaram uma emancipação, a partir das necessidades que surgem, de forma autônoma, transformando as ações desenvolvidas em novas ações.

Segundo Nogueira (2019, p. 251), em relação ao professor de Matemática, não basta

[...] ter domínio dos conceitos e procedimentos da Matemática produzidas
historicamente, é mister que conheça a totalidade, os fundamentos
epistemológicos, sua evolução histórica, a relação da matemática com
a realidade, seus usos, suas diferentes linguagens, para que possam
compreender a práxis. Na práxis e baseado na práxis, o sujeito estabelece
a sua relação com o mundo, com a realidade como um todo estruturado,
dialético que venha ser compreendido, ou seja, como as múltiplas relações
e determinações que fazem o professor de matemática ser quem ele é.

Com essa consciência, há possibilidade de transformações das condições institucionais e sociais do ensino. Dessa forma, a perspectiva de Contreras (2012), em relação à autonomia de professores, coexistem em aspectos pessoais (compromissos moral e ético; e sociais), de relacionamento e dos valores que os guiam. Logo, é uma questão humana, homens vivos, dialógicos e não meramente técnica; um elemento colaborativo, uns ajudando os outros. Bakhtin (1999, p. 14-15), por sua vez, valoriza o dialogismo e afirma:

\footnotetext{
[...] sua natureza social, não individual: a fala está indissoluvelmente ligada às condiç̃es da comunicação, que, por sua vez, estão sempre ligadas às estruturas sociais. Toda enunciação, fazendo parte de um processo de comunicação ininterrupto, é um elemento do diálogo, no sentido amplo do termo, englobando as produções escritas.
} 
Só existe essa autonomia na docência se compreendermos a importância das parcerias, dos atos dialógicos. Essa autonomia, evidenciada por Contreras (2012), separase da autossuficiência, para aproximar-se da emancipação, do empoderamento. Com esse entendimento, abrimos caminhos para dialogarmos sobre as possibilidades de parcerias e os tipos de parcerias.

\section{PARCERIAS NA DOCÊNCIA}

A parceria entre Universidade e Escola Básica é um tema recente nas pesquisas e no contexto brasileiro "[...] são poucos os estudos específicos até o momento sobre essa questão. Já na literatura internacional, estão disponíveis produções acadêmicas desde a primeira metade dos anos 90 a respeito da temática." (FOERSTE, 2004, p. 1). No entanto, o autor sinaliza que é de grande importância para a profissão docente que haja "a parceria na formação dos profissionais do ensino enquanto uma prática de colaboração construída na interface entre universidade e professores da escola básica." (FOERSTE, 2004, p. 8)

Neste texto, na perspectiva da aproximação universidade e escola, dialogaremos com as perspectivas de parceria na formação de professores, intituladas dirigida, oficial e colaborativa (Figura 5).

Figura 5 - Tipos de parcerias

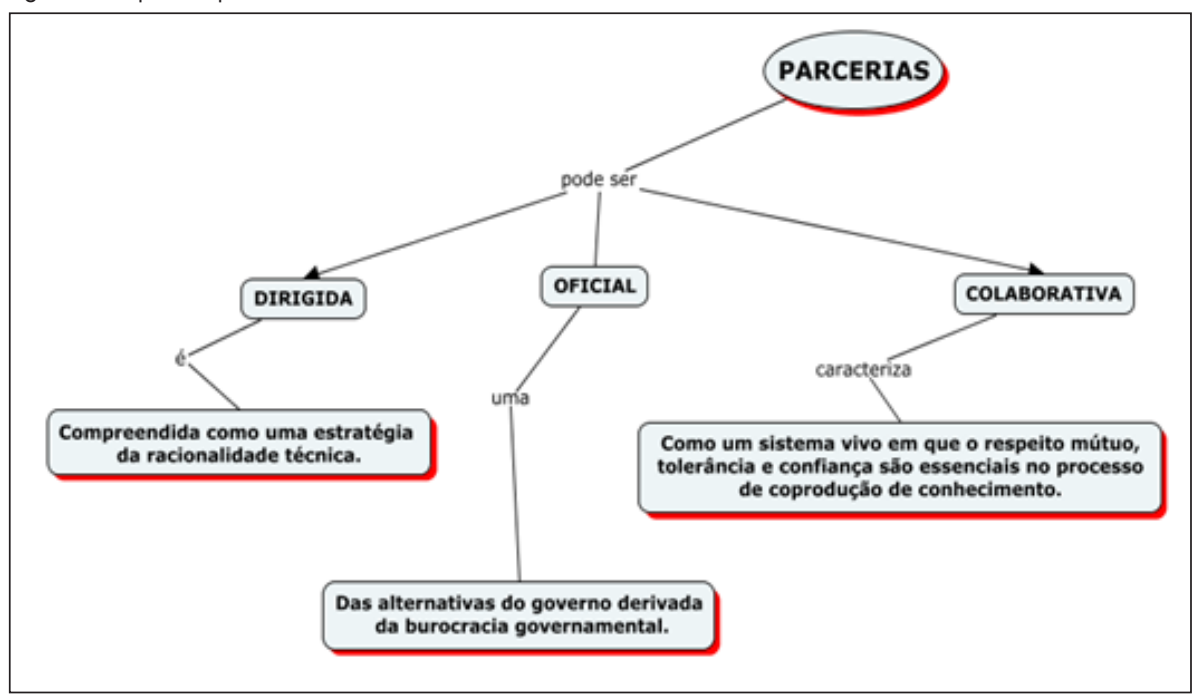

Fonte: elaborada pelos autores com base em Nogueira (2019). 
As parcerias dirigidas movimentam o direcionamento de ações a fim de um determinado olhar, perdendo autonomia da academia no processo de construção dos conhecimentos, nessa modalidade de relação, "a instituição formadora - a universidade detêm todo o poder de decisão do que fazer e como fazer." (FOERSTE; LUDKE, 2003, p. 167).

Derivada da "burocracia na busca de alternativas mais adequadas para a execução das propostas de reformas públicas" (FOERSTE; LUDKE, 2003, p. 168), as parcerias oficiais, na visão de Foerste (2004, p. 3), assumem "características mais formais, com atenção especial por parte do poder público, que passou a se ocupar em estabelecer políticas públicas, sobretudo no processo de formação inicial proporcionado pela universidade, com a definição de normas para a sua implementação."

Na parceria oficial, "...] os interesses não coincidem com os da academia e dos professores e dos professores da Educação Básica." (FOERSTE, 2004, p. 87). 0s projetos e os programas ficam à mercê das mudanças políticas e interesses do poder público, os quais deveriam ser desenvolvidos de forma contínua por meio de investimentos e não de mudanças a cada governo.

Sendo assim, podemos inferir que tanto a parceria dirigida quanto a oficial não dão conta de arquitetar e implementar transformações significativas para a formação de professores.

Observando a Figura 5 (cinco), apresentada anteriormente, constatamos que a possibilidade de autonomia do professor está ancorada na parceria colaborativa, pois ela, segundo Nogueira (2019, p. 103), "cria condições para que os sujeitos, [...] estabeleçam negociações concretas, construam o conhecimento, [...], respeitando os interesses específicos, discutindo e interferindo no discurso dos outros." No entanto, queremos evidenciar que a parceria que possibilita a autonomia de professores é a parceria colaborativa, mas ela é um processo.

Foerste (2004) afirma ser muito importante para a profissão docente que se deem as formações por meio de parcerias entre a universidade e a escola básica, por práticas colaborativas.

Compreendemos que a colaboração é uma prática que proporciona o desenvolvimento da docência. Para Oliveira e Magalhães (2011, p. 66, grifo nosso), as ações de colaboração:

[...] se constituem práticas sociais que têm como objeto a introdução de transformaç̃̃es quanto a necessidades dos contextos dos participantes e implicam certo grau de conhecimento da realidade que objetivam transformar e das necessidades que querem satisfazer, com a finalidade de empoderar os participantes por meio de uma prática crítica e criativa. 
Diante disso, podemos inferir que a autonomia dos professores não pode ser em uma perspectiva dirigida, nem oficial, mas na parceria colaborativa, viés de colaboração, pois essa é de caráter social, e não individual, apenas estado e atributos das pessoas, "mas um exercício, uma qualidade da vida que vivem." (CONTRERAS, 2012, p. 215). Portanto, é necessário dialogarmos com os sistemas vivos, processos e situações sociais, as quais as pessoas conduzem-se, reconstroem-se a todos os momentos.

Nessa perspectiva, Nogueira (2019) enfatiza que a profissão de educador é uma prática social e, como tantas outras, é uma forma de intervir no meio social. Podemos, desse modo, entender que, como prática social, a ação docente não se constitui isoladamente, mas num contexto essencialmente de um trabalho coletivo, de encontros e diálogos.

A autora acrescenta que para estabelecer esse contexto e o estabelecimento da parceria colaborativa, só é possivel se

[...] os sujeitos, desenvolverem laços que thes permitam expressar, seus saberes, conflitos e essencialmente comunicar interesses em comuns. [...] de modo que todos têm vez e voz nesse processo. Deixam de ser objetos de pesquisa e passam nessa parceria a ser sujeitos de aprendizagem, pesquisador de suas ações, conhecedor da realidade o qual está inserido, sujeitos transformadores. (NOGUEIRA, 2019, p. 105).

Partindo dessa premissa, a autonomia conforme afirma Contreras (2012, p. 217),

[...] não está desvinculada das conexões com as pessoas [...] nem tão pouco é um padrão fixo de atuações. Antes apresenta uma busca e um aprendizado contínuos uma abertura a compreensão e reconstrução contínua da própria identidade profissional, ou de sua maneira de realizá-la em cada caso.

Logo, compreendemos que a parceria colaborativa propicia possibilidades para a autonomia do professor, visto que ela se constrói no encontro, com o desenvolver-se das convicções e intenções profissionais, intercedidas pelo entrosamento e pelo diálogo, portanto, entender as probabilidades e expectativas sociais é tão importante como compreender-se socialmente por parte dos profissionais (CONTRERAS, 2012).

Para além, a autonomia profissional no contexto social das ações de ensino deve ser compreendida pelas qualidades das relações sociais com os outros, logo a importância da alteridade, visto que nos constituímos a partir do outro, o outro possibilita-nos ser autônomos, o outro propicia-nos empoderarmos. 
Essa parceria via pesquisa colaborativa pressupõe interação entre pesquisa e formação, que apresentaremos a seguir.

\section{PESQUISA COLABORATIUA}

Em busca dessa formação inicial de professores pela aproximação entre universidade e escola, por meio do trabalho colaborativo, apresentamos a pesquisa colaborativa, que possui, em seu bojo, a colaboração, a reflexão crítica e a produção de conhecimento.

Kemmis (1986) apresenta a pesquisa colaborativa com características em tentar compreender, interpretar e solucionar os problemas dos professores em seus cotidianos escolares, proporcionando a transformação da cultura docente, criando condições para o desenvolvimento profissional.

Em nossa compreensão, a pesquisa colaborativa possui a perspectiva de coprodução dos conhecimentos por meio dos processos formativos, que os partícipes desenvolvem entre si.

Ibiapina (2008) entende, como objetivo da pesquisa colaborativa, transformar uma determinada realidade educativa, levando tempo para ser concretizada, em ações formativas, buscando a valorização do pensamento do próximo, na construção dos diálogos de autonomia e respeito mútuo.

A prática da pesquisa colaborativa é dada por processos interativos e de produção do conhecimento em uma sistemática reflexiva pelas ações práticas à crítica das próprias ações desenvolvidas durante a pesquisa.

Sendo esse o diferencial da pesquisa colaborativa, ou seja, a produção de conhecimento entre os partícipes, as ações críticas das próprias ações, que desenvolvem durante a pesquisa, bem como a possibilidade de transformação da realidade que movimenta a pesquisa, calcada na valorização das práticas colaborativas, por meio das negociações coletivas.

Dessa forma, o desenvolvimento da pesquisa colaborativa envolve ações formativas em um ambiente de diálogo; valorização do pensamento do outro, compreensão do outro e de si mesmo, diante as realidades por meio do compartilhamento das experiências.

Contudo, para desenvolver essa formação, tem de haver articulação dos conhecimentos teóricos - práticos, como aponta Cochran-Smith e Lytle (1999), bem como Ponte (2002), os quais referem que a articulação tem de estar em unicidade, que dialogar para a construção dos conhecimentos, possibilitando ao desenvolvimento da profissionalização. 
Além do que, como indica Silva (2013), os conhecimentos necessários à profissão docente são tidos pela articulação entre a teoria e a prática. Nesse contexto, a teoria e a prática caminham juntas, relacionando-se, como afirma Ghedin (2002, p. 133), para quem "não existir teoria sem a prática e nem prática sem a teoria, desta forma não é possível separarmos o que é inseparável."

Quando tratamos de teoria não estamos mobilizando apenas as teorias que aprendemos na graduação ou nos cursos de formação, mas também as experiências das práticas que o professor possui. Logo, pensar na prática, numa concepção reflexiva, como sendo "um modo possível dos professores interrogarem as suas práticas de ensino [...] uma prática reflexiva confere poder aos professores e proporciona oportunidades para o seu desenvolvimento." (OLIVEIRA; SERRAZINA, 2002, p. 1).

Observamos que o pesquisador, nesse tipo de pesquisa, tem de desenvolver um ambiente colaborativo, estimulando a manifestação do pensamento durante os diálogos por meio de ações formativas, para que consiga desenvolver a reflexão dos professores e, assim, uma possível transformação da realidade, a partir das necessidades reais, que os professores possuem.

Dessa forma, também oportuniza aos partícipes durante o desenvolvimento da pesquisa colaborativa uma coprodução na investigação, não tendo os pares que participar das tarefas formais do pesquisador, porém não os proíbe caso seja um interesse do mesmo.

Tendo o pesquisador que, por meio do diálogo e colaboração com os envolvidos na pesquisa, fornecer a continuidade, haja vista que as mudanças ocorrem dependendo das situações proporcionadas, sendo, neste aspecto de colaboração, que há paridade e as iguais responsabilidades, não significam a igualdade de papéis nas decisões ou ações durante a pesquisa (WALLAT et al., 1981).

Nesse ambiente propiciado ao diálogo, a pesquisa colaborativa possibilita o confronto de perspectivas, interpretações que, por meio das negociações e ações planejadas, as reflexões críticas e os conhecimentos são desenvolvidos e produzidos, ampliando, assim, os conhecimentos pela tomada de consciência das ações durante o desenvolvimento do trabalho.

A reflexão na pesquisa colaborativa, como aponta Caetano (2003), usa a investigação para ajudar a compreender criticamente as várias ações que o professor tende a compreender-se sobre a situação, sobre si próprio, sobre a ação e sobre as suas possiveis consequências.

No contexto educacional, a reflexão é mobilizada com a conscientização dos próprios atos do professor, isto é, sobre o próprio professor, exercendo o pensamento sobre as suas ideias e suas ações, examinando, modificando e levando o professor a formar uma teoria sobre a sua prática (ZEICHNER, 1993). 
Para desenvolver essa formação na articulação teoria - prática, a fim de tornar sujeitos conscientes e engajados na transformação de sua realidade, é necessário estar no "chão" da escola para desenvolvermos reflexões quanto à realidade, bem como construir conhecimentos para formarmos profissionais críticos, que busquem transformações e compreendam o verdadeiro papel social da profissão docente.

Para Ibiapina (2008), a reflexão envolve mais do que resolver problemas e dilemas, mais que apenas pensar sobre determinado assunto, pois temos que considerar o professor como um ser histórico, que possui objetivos e limites, que desenvolve ações pela sua constituição como pessoa, como docente e, por esse motivo, não podemos compreender a reflexão como passos a serem realizados.

Dessa forma, no viés da profissionalização docente, ao pensarmos no processo formativo dos professores de Matemática em formação inicial é necessário vislumbrarmos parceria entre universidade e escola básica, pois são agências formadoras (MIZUKAMl, 20052006). Sabemos que, por meio das agências formadoras, mediante trabalhos integrados, ocorre o favorecimento das ações formativas.

Nascimento, Almeida e Passos (2016) explicitam que uma das questões centrais na formação inicial de professores é o distanciamento entre os contextos da formação e do trabalho. Os autores enfatizam que "[...] a percepção desse problema tem levado a uma série de experiências que tomam como eixo a busca de parcerias entre universidade e escola, no sentido de aproximar o conhecimento acadêmico do conhecimento produzido pelos professores no campo de atuação." (NASCIMENTO; ALMEIDA; PASSOS, 2016, p. 11).

No que tange a essas tentativas de aproximações da formação inicial e continuada, podemos inferir que, no Brasil, o foco de análise dessa conexão é a identidade e a profissionalidade docente. Nogueira (2019, p. 76) afirma que "a construção coletiva dos saberes docentes, a reflexão sobre a prática, a realidade educativa e social, tem contribuído para o processo de formação profissional ligado à docência."

\section{CONSIDERAÇÕES FINAIS}

A partir de todas essas discussões, as análises levaram-nos a concluir que é necessário que a universidade possibilite a esses profissionais a compreensão de seu verdadeiro papel social, na tentativa de entender-nos criticamente em relação aos valores e às práticas que atuamos. 
É necessário o diálogo para a compreensão que a autonomia dos professores não significa mais ser massa de manobra, mas capacidade de intervir nas decisões políticas pelas quais cedem-se responsabilidade à educação, bem como a intervenção nas condições pelas quais as cessões podem ser usadas para uma maior vinculação social no desenvolvimento do bem comum (CONTRERAS, 2012), visto que não podemos falar em autonomia, e até mesmo em empoderamento, se não tivermos uma clara consciência crítica do nosso papel social e político, bem como o papel da escola e da educação como um todo.

Temos que recuperar o debate sobre as formas de parcerias no âmbito da educação e da formação de professores de Matemática. Ao mesmo tempo é necessário proteger, cuidar, expandir e divulgar as experiências, pesquisas que signifiquem a vivência da coletividade, tentando o estabelecimento de parcerias colaborativas e o empoderar-se dos professores.

Compreendemos que quando a pesquisa colaborativa é desenvolvida pela aproximação da Universidade com a escola, em reflexão crítica na articulação teoria - prática, possibilita a construção de conhecimentos durante os processos da formação inicial a fim da profissionalização docente.

A guisa de discussão final, retomamos questões proeminentes, discutidas ao longo do texto, e, a partir delas, as análises conduzem-nos a concluir que é preciso que a universidade possibilite a esses profissionais a compreensão de seu verdadeiro papel social, na tentativa de compreenderem-se criticamente em relação aos valores e às práticas que atuam.

\section{REFERÊNCIAS}

BAKTHIN, M. Marxismo e filosofia da linguagem. 9. ed. São Paulo: Editora Hucitec, 1999.

BROUSSEAU, G. Os diferentes papéis do professor. In: PARRA, C.; SAIZ, I. (org.). Didática da matemática: reflexões psicopedagógicas. Porto Alegre: Artmed, 2008.

CAETANO, A. Para uma conceptualização da reflexão na investigação-acção. Revista Portuguesa de Pedagogia, p. 113-133. 2003.

COCHRAN-SMITH, M.; LITLE, S. L. Relationship of knowledge and practice: teacher learning in communities. Review of Research in Education, n. 24, p. 249-305, 1999.

CONTRERAS, J. Autonomia de professores. 2. ed. Tradução: Sandra Trabuco Valenzuela. São Paulo: Cortez, 2012 
FOERSTE, E.; LÜDKE, M. Avaliando experiências concretas de parceria na formação de professores. Avaliação/Rede de Avaliação Institucional da Educação Superior - RAIES, v. 8, n. 4, p. 163-182, dez. 2003.

FOERSTE, E. Parceria na formação de professores. Revista lberoamericana de Educación, p. 1-12, 2004.

GATTI, B. A. Formação de professores e carreira: problemas e movimentos de renovação. Campinas, SP: Autores Associados, 1997.

GHEDIN, E. Professor reflexivo: da alienação da técnica à autonomia da crítica. In: PIMENTA, S.; GHEDIN, E. (org.). Professor Reflexivo no Brasil - gênese e crítica de um conceito. 2. ed. São Paulo: Cortez, 2002.

IBIAPINA, I. M. L. M. Pesquisa colaborativa: investigação, formação e produção de conhecimentos. Brasilia DF: Líber Livro Editora, 2008.

IMBERNÓN, F.; CAUDURO, M. A formação como desenvolvimento profissional dos professores de educação física e as políticas públicas. Revista de Ciências Humanas, v. 14, n. 23, p. 17-30, 2013.

IMBERNÓN, F. Formação docente e profissional: formar-se para a mudança e a incerteza. 9. ed. São Paulo: Cortez, 2011. v. 14.

KEMMIS, S. Approachests to Staff Development. In: WINDEEN. M. F.; ANDREWS, I. Staff developmente for school improvement. Philadelphia: Imago Publishing, 1986.

LIBERALI, F. C. Formação crítica de educadores: questões fundamentais. 2. ed. Campinas, SP: Pontes Editores, 2012. (Coleção Novas Perspectivas em Linguística Aplicada, v. 8).

MAGALHÃES, M. C.; LIBERALI, F. C. 0 Interacionismo Sociodiscursivo em Pesquisa com Formação de Educadores. Calidoscópio, v. 2, n. 2, 2004.

MIZUKAMI, M. G. N. Aprendizagem da docência: professores formadores. Revista E-Curriculum, v. 1, n. 1, dez./jul. 2005-2006.

NASCIMENTO, M. G.; ALMEIDA, P. C. A.; PASSOS, L. F. Formação docente e sua relação com a escola. Rev. Port. de Educação, v. 29, n. 2, dez. 2016.

NOGUEIRA, K. F. P. Necessidades formativas na constituição do professor de matemática em formação e em exercício: diálogos e conexões. 2019. Tese (Doutorado em Educação Matemática) - Instituto de Matemática, Universidade Federal de Mato Grosso do Sul, Campo Grande, 2019.

NÓVOA, A. 0 passado e o presente do professor. In: NÒVOA, A. Profissão professor. Porto: Porto Ed., 1995.

OLIVEIRA, I.; SERRAZINA, L. A reflexão e o professor como investigador. In: GTI (org.). Reflectir e investigar sobre a prática profissional. Lisboa: APM, 2002. 
OLIVEIRA, W.; MAGALHÃES, M. C. C. A colaboração crítica como categoria de análise da atividade docente. In: MAGALHÃES, M. C. C.; FIDALGO, S. S. (org.). Questões de método e de linguagem na formação docente. Campinas, SP: Mercado de Letras, 2011. p. 65-76.

PONTE, J. P. A vertente profissional da formação inicial de professores de matemática. Revista da Sociedade Brasileira de Educação Matemática, n. 1la, p. 3-8, 2002.

SOUZA. J. Possibilidades de reflexão crítica e colaboração em contextos de formação continuada: para além do discurso. 2012. Dissertação (Mestrado em Educação) - Universidade Federal do Piaú, Teresina, 2012.

SILVA, L. N. D. Formação de professores: dilemas e desafios da relação entre teoria e prática. 1. ed. Curitiba: Appris, 2013.

ZEICHNER, K. A formação reflexiva de professores: ideias e práticas. Lisboa: Educa. 1993.

WALLAT, C. et al. Issues related to action research in the classroom - The teacher and researcher as a team. In: GREEEN, J. L.; WALLAT, C. (ed.). Ethnography and language in educational settings. Norwood: Ablex, 1981 .

Endereço para correspondência: Instituto de Matemática, Cidade Universitária, Avenida Costa e Silva, s/n, 79070-900, Pioneiros, Mato Grosso do Sul, Brasil; sandalo.patricia13@gmail.com 
